\title{
Knowledge, attitudes, and behavioural risk factors regarding zoonotic infections among bushmeat hunters and traders in Nsukka, southeast Nigeria
}

\author{
Kingsley Uchenna Ozioko', Chris Ikem Okoye'1, Rose Nduka Obiezue', Raymond Awudu Agbu² \\ ${ }^{1}$ Parasitology and Public Health Research Unit, Department of Zoology and Environmental Biology, University of Nigeria, Nsukka, Nigeria; \\ ${ }^{2}$ Central Laboratory Unit, Federal University Wukari, Wukari, Nigeria.
}

OBJECTIVES: In light of the dramatic spread of Ebola virus in some parts of Africa and the 2014 outbreak in Nigeria, a study was conducted to evaluate bushmeat dealers' knowledge and attitudes about zoonotic infections and the risk of transmission to humans.

METHODS: A cross-sectional survey was conducted in a community in Nsukka, southeast Nigeria. Hunters $(\mathrm{n}=34)$ and bushmeat traders $(n=42)$ were interviewed. A semi-structured questionnaire was used to generate the data. The Fisher exact test was used to evaluate the significance of differences between these groups.

RESULTS: Only $11.8 \%$ of the hunters, as compared to $35.7 \%$ of the traders, had no knowledge of possible causes of zoonotic infections ( $\mathrm{p}<0.05$ ). However, $64.7 \%$ of the hunters, compared to $38.1 \%$ of the traders, were ignorant regarding the responsibility of public health personnel and veterinarians ( $\mathrm{p}<0.05)$, and $76.5 \%$ of the hunters compared to $42.9 \%$ of the traders were ignorant regarding the existence of zoonoses in Nigeria $(\mathrm{p}<0.05)$. A statistically significant difference was also found between these groups regarding the risk of contracting an infection from ectoparasites $(\mathrm{p}<0.05)$. The attitudes of respondents towards zoonotic diseases did not differ significantly between the groups.

CONCLUSIONS: The level of awareness about zoonotic diseases was low in this area, underscoring the need for interventions.

KEY WORDS: Knowledge, Attitude, Risk, Zoonotic, Wildlife, Pathogen

\section{INTRODUCTION}

Wildlife serves as food for males and as a reservoir host of pathogens that cause disease in males. Human contacts with a wide range of wildlife tissues and fluids, either directly or indirectly thr-

\section{Correspondence: Kingsley Uchenna Ozioko}

Parasitology and Public Health Research Unit, Department of Zoology and Environmental Biology, University of Nigeria, Nsukka 400241, Nigeria

E-mail: ukingsley82@yahoo.com

Received: Apr 4, 2018 / Accepted: Jun 16, 2018 / Published: Jun 16, 2018

This article is available from: http://e-epih.org/

(C) This is an open-access article distributed under the terms of the Creative Commons Attribution License (http://creativecommons.org/licenses/by/4.0/), which permits unrestricted use, distribution, and reproduction in any medium, provided the original work is properly cited.

(C) 2018, Korean Society of Epidemiology ough arthropod bites during hunting and processing of bushmeat, expose humans to a risk of zoonoses [1]. Certain individuals with occupational exposure, such as traders (chop bar owners, bushmeat vendors), or individuals who participate in outdoor recreational activities, such as hunters, are at a higher risk of contracting and spreading infections from bushmeat. The percentage of wild animals that are carriers for zoonotic diseases is increasing, resulting in growing concerns for human safety and control [1]. Awareness is the most important strategy for preventing occupationally acquired infectious diseases. Thus, knowledge and awareness about the risk of zoonotic diseases is a prerequisite for effective disease control [2]. Zoonotic infections are among the most common on earth, accounting for more than $60 \%$ of all human infectious diseases [3]. Most emerging zoonotic diseases are of viral origin and are transmitted by vectors [4], which for the most part are wildlife $[5,6]$. Some of the most notorious disease outbreaks of all time were the result of zoonotic pathogens. Perhaps the most widely 
known of these pathogens is the Ebola virus. This disease has led to major outbreaks in some parts of Africa, and may have killed millions of people throughout several centuries. The route of transmission has been linked to bushmeat, and unusual behaviours exhibited by the inhabitants of Nsukka during the outbreak in Nigeria were alarming. There was an obvious reduction in the demand for bushmeat consumption in the area, to the point that the Association of Bushmeat Traders and Hunters had to organise an event highlighting public consumption of their wares in public, in an effort to boost demand. Nigeria was declared to be free of Ebola virus disease by the World Health Organisation on October 20, 2014, but the federal government has put in place an emergency programme to monitor all border activity to keep Nigeria safe following the 2018 outbreak in the Democratic Republic of the Congo [7]. Therefore, assessing the knowledge, attitudes, and behavioural risk factors associated with the prevention and control of zoonotic diseases in Nigeria is crucial in order to identify gaps that may encourage the spread of any outbreak of similar diseases in the future. In Nsukka, wildlife has been associated with several important zoonotic pathogens [7]. Currently, inadequate data exist on the knowledge, attitude, and behavioural risk factors for zoonotic diseases in Nsukka generally and for bushmeat-borne zoonotic diseases in particular. Therefore, the objective of this study was to assess the level of knowledge, attitudes, and behavioural risk factors regarding zoonotic infections among the bushmeat dealers in the study area. The intention is that the baseline information generated will facilitate the development of effective joint veterinarymedical policies and guidelines for controlling emerging zoonotic diseases in the area. Collecting information and assessing safe work practices and attitudes among at-risk populations can provide a suitable format to evaluate existing programs and to identify effective strategies for behavioural changes.

\section{MATERIALS AND METHODS}

\section{Study area and population}

This study was carried out between October 2016 and February 2017 among bushmeat dealers based in the Nsukka Senatorial Zone of Enugu State, Nigeria. Nsukka is located in the northern part of Enugu State, between longitude $7^{\circ} 08^{\prime}$ and $7^{\circ} 20^{\prime}$ east and latitude $6^{\circ} 46^{\prime}$ and $6^{\circ} 49^{\prime}$ north [8]. It is made up of 7 densely populated Local Government Areas: Igbo-Etiti, Uzo-Uwani, Isi-Uzo, Nsukka, Udenu, Igbo-Eze North, and Igbo-Eze South. Its population accounts for over 49\% of Enugu State. As of 2007, the Nsukka Cultural Zone had an estimated population of 1,377,001 [8]. The town of Nsukka is known as the location of the first full-fledged indigenous university in Nigeria (University of Nigeria, Nsukka). Bushmeat is transported from forests and grassland areas, where hunting mainly takes place, to markets within local communities or to larger markets in urban centres, where it is then sold to bushmeat traders who buy them directly from hunters (the source of the supply).

\section{Sample size}

No sampling was done. All registered full-time hunters and traders during the given period were eligible to take part in the study. The total number of subjects was 76 .

\section{Study design}

The study was designed to cover all registered hunters in the area who hunted and transported bushmeat to markets and all registered traders who bought them directly from the hunters, because doing so was considered feasible. A compilation of names was first produced through the local chairmen of bushmeat association. The list was used to contact them for the data collection process, which encountered some delays, as some had no mobile phones. Given the buy-in from union chairmen, all dealers were willing to participate in the study. The questionnaire was divided into 4 major areas. The category of demographics included 3 questions that provided vital information covering a wide range of socio-demographic areas. Basic knowledge about zoonotic infections was assessed through 5 questions that were related to different aspects of zoonoses, ranging from basic and general information to knowledge about transmission and prevention. The section on attitudes towards zoonoses contained 4 yes/no statements measuring the attitude of respondents towards different aspects of zoonoses. The category of behavioural risk factors for zoonotic infections had 4 questions covering basic sources of zoonotic links.

\section{Data collection}

A semi-structured questionnaire was used to obtain data from the participants. The focus of the questionnaire was on aspects of registered full-time hunters and traders' knowledge that were considered important for the identification and perception of zoonoses. A total of 42 bushmeat traders and 34 bushmeat hunters responded to an interviewer-guided questionnaire, which probed demographic data and information on knowledge, attitudes, and risk factors related to zoonoses, with a particular emphasis on bushmeat-borne zoonoses. It was designed to be completed within 20 minutes for an average respondent. All technical terms in the questionnaire were translated into the Igbo language and explained by the interviewer. Confidentiality was assured to each participant, and demographic data of the study participants, including sex, marital status, and educational status, were collected and presented in a tabular format.

\section{Data analysis}

The collected data were processed using SPSS version 20 (IBM Corp., Armonk, NY, USA). The Fisher exact test was used to evaluate the significance differences, with $\mathrm{p} \leq 0.05$ considered to indicate significant differences. Frequency and percentage were computed for all variables.

\section{Ethical statement}

Ethical approval was not required in this study, although authorization was sought and received from the chairman of the Associ- 
ation of Hunters and Bushmeat Traders. At an individual level, verbal consent was received from each participant before data collection.

\section{RESULTS}

\section{Demographic characteristics}

Of the 76 participants, more were male $(65.8 \%)$ than female (34.2\%) (Table 1). As reported by the respondents, $81.6 \%$ were married and $18.4 \%$ were single. In terms of educational status, $78.9 \%$ of the respondents had a secondary education, $18.4 \%$ had only a primary education, and 1 hunter $(2.6 \%)$ had a tertiary education.

\section{Knowledge of respondents (hunters and traders) about zoonotic diseases}

In order to gain an understanding of what participants knew, understood, and believed regarding zoonotic diseases and health,

Table 1. Demographic characteristics of the subjects

\begin{tabular}{lccc}
\hline Characteristics & $\begin{array}{c}\text { Hunters } \\
(\mathrm{n}=34)\end{array}$ & $\begin{array}{c}\text { Traders } \\
(\mathrm{n}=42)\end{array}$ & $\begin{array}{c}\text { Total } \\
(\mathrm{n}=76)\end{array}$ \\
\hline Sex & 34 & 16 & $50(65.8)$ \\
$\quad$ Male & - & 26 & $26(34.2)$ \\
$\quad$ Female & 4 & 10 & $14(18.4)$ \\
Educational status & 28 & 32 & $60(78.9)$ \\
$\quad$ Primary level & 2 & - & $2(2.6)$ \\
$\quad$ Secondary level & & & \\
$\quad$ Tertiary level & 22 & 40 & $62(81.6)$ \\
Marital status & 12 & 2 & $14(18.4)$ \\
$\quad$ Married & Single & &
\end{tabular}

Values are presented as number or number (\%). participants were asked to supply information based on their level of awareness (Table 2). Very few participants were aware of the existence of zoonotic infections that could be transmitted by handling, processing, or eating bushmeat. Regarding knowledge of the causes of zoonotic infections, $11.8 \%$ of the hunters had no knowledge of the possible cause of such infections, compared to $35.7 \%$ of the traders, which was a significant difference between the groups $(\mathrm{p}<0.05)$. Approximately half of the hunters $(73.5 \%)$ and the traders (52.4\%) were not aware of how to reduce the likelihood of contracting work-related infections. A significant difference was found between hunters $(64.7 \%)$ and traders $(38.1 \%)$ in terms of views regarding the responsibility of public health personnel and veterinarians for providing information about zoonotic infections $(\mathrm{p}<0.05)$. A statistically significant difference was also found between the groups in terms of awareness of the existence of zoonoses in wild animals in Nigeria, as $76.5 \%$ of hunters thought that there were none, compared to $42.9 \%$ of traders $(\mathrm{p}<0.05)$.

\section{Attitudes of respondents (hunters and traders) towards zoonotic diseases}

A majority of respondents had negative attitudes towards zoonotic infections (Table 3). However, $52.9 \%$ of the hunters and $28.6 \%$ of the traders expressed no concern that they might acquire an infection from bushmeat. Regarding wearing protective gear during contact with animals, the overwhelming majority of respondents ( 85.3 and $88.1 \%$ of hunters and traders, respectively) considered doing so to be unnecessary. Correspondingly, a high percentage of both the hunters (91.2\%) and the traders (76.2\%) valued bushmeat more than their health. The vast majority of respondents ( $94.1 \%$ of the hunters and $90.5 \%$ of the traders) did not seek medical consultations regarding the possibility of a zoonotic disease when sick. Attitudes towards zoonotic diseases did not differ significantly between the groups.

Table 2. Respondents' knowledge of zoonotic diseases

\begin{tabular}{|c|c|c|c|}
\hline Variables & $\begin{array}{c}\text { Hunters } \\
(n=34)\end{array}$ & $\begin{array}{l}\text { Traders } \\
(n=42)\end{array}$ & p-value \\
\hline \multicolumn{4}{|c|}{ Knowledge regarding the existence of zoonoses } \\
\hline Yes & $5(14.7)$ & $4(9.5)$ & 0.50 \\
\hline No & $29(85.3)$ & $38(90.5)$ & \\
\hline \multicolumn{4}{|c|}{ Knowledge that zoonotic diseases are caused by harmful germs } \\
\hline Yes & $30(88.2)$ & $27(64.3)$ & 0.02 \\
\hline No & $4(11.8)$ & $15(35.7)$ & \\
\hline \multicolumn{4}{|c|}{ Knowledge of ways to reduce zoonotic infections } \\
\hline Yes & $9(26.5)$ & $20(47.6)$ & 0.10 \\
\hline No & $25(73.5)$ & $22(52.4)$ & \\
\hline \multicolumn{4}{|c|}{ Knowledge that public health personnel and veterinarians are responsible for reporting zoonoses } \\
\hline Yes & $12(35.3)$ & $26(61.9)$ & 0.04 \\
\hline No & $22(64.7)$ & $16(38.1)$ & \\
\hline \multicolumn{4}{|c|}{ Knowledge that one can be infected here in Nigeria } \\
\hline Yes & $8(23.5)$ & $24(57.1)$ & 0.005 \\
\hline No & $26(76.5)$ & $18(42.9)$ & \\
\hline
\end{tabular}

Values are presented as number (\%). 
Table 3. Respondents' attitudes towards zoonotic diseases

\begin{tabular}{|c|c|c|c|}
\hline Variables & Hunters $(n=34)$ & Traders $(n=42)$ & p-value \\
\hline \multicolumn{4}{|c|}{ Concerned about contracting a work-related zoonosis } \\
\hline Yes & $16(47.1)$ & $30(71.4)$ & 0.36 \\
\hline No & $18(52.9)$ & $12(28.6)$ & \\
\hline \multicolumn{4}{|c|}{ Concerned about using protective measures } \\
\hline Yes & $5(14.7)$ & $5(11.9)$ & 0.74 \\
\hline No & $29(85.3)$ & $37(88.1)$ & \\
\hline \multicolumn{4}{|c|}{ Agree that benefits of bushmeat consumption do not outweigh any health risks } \\
\hline Yes & $3(8.8)$ & $10(23.8)$ & 0.13 \\
\hline No & $31(91.2)$ & $32(76.2)$ & \\
\hline \multicolumn{4}{|c|}{ Seek a medical consultation when needed } \\
\hline Yes & $2(5.9)$ & $4(9.5)$ & 1.00 \\
\hline No & $32(94.1)$ & $38(90.5)$ & \\
\hline
\end{tabular}

Values are presented as number (\%).

Table 4. Behavioural risk factors for zoonotic infections

\begin{tabular}{lcc}
\hline Variables & Hunters $(\mathrm{n}=34)$ & Traders $(\mathrm{n}=42)$ \\
\hline Have previously contracted an infection from bushmeat & & $4(9.5)$ \\
Yes & $3(8.8)$ & $38(90.5)$ \\
No & $31(91.2)$ & $2(4.8)$ \\
Have been bitten by wildlife used for bushmeat within 12 mo & $30(88.2)$ & $40(95.2)$ \\
Yes & $4(11.8)$ & $35(83.3)$ \\
No & $26(76.5)$ & $7(16.7)$ \\
Have been bitten by ectoparasites & $8(23.5)$ & 0.56 \\
Yes & $29(85.3)$ & $16(38.1)$ \\
No & $5(14.7)$ & $26(61.9)$ \\
Processes bushmeat at home or shares house with wild animals & $<0.001$ \\
Yes & & $<0.001$ \\
No
\end{tabular}

Values are presented as number (\%).

\section{Behavioural risk factors for zoonotic infections (hunters and traders)}

Table 4 presents the distribution of responses regarding behavioural risk factors for zoonotic diseases. Behavioural risk factors for zoonosis varied significantly between the groups $(p<0.05)$. A high percentage of traders and hunters had never in their life contracted an infection from bushmeat (91.2 and 90.5\%, respectively). Furthermore, $88.2 \%$ of the hunters stated that they had been bitten by wildlife used for bushmeat within the last 12 months, while $95.2 \%$ of the traders said that they had not $(\mathrm{p}<0.001)$. Additionally, 85.3 and $38.1 \%$ of the hunters and traders, respectively, reported sharing their house with animals or processing animals at home regularly (at least weekly), which was a significant difference between the groups $(\mathrm{p}<0.001)$. Only a few of the participants were aware of the risk of direct transmission via contact with the placenta or skin-to-skin contact with animals when processing or sharing their house with a wild animal.

\section{DISCUSSION}

Up-to-date knowledge, attitudes, and behaviours regarding zoonotic diseases among high-risk groups are vital for the formulation and effective implementation of appropriate disease prevention and control strategies in any given area [9]. The results obtained from this study demonstrated that male respondents represented about $65.8 \%$ of those who were involved in processing and hunting bushmeat; this shows that it was entirely male occupation in the study area, meaning that men were at the highest risk for bushmeat-borne zoonotic infections. Participants' literacy level seemed to be sufficiently high, as $78.9 \%$ of the respondents had attended secondary education, while $2.6 \%$ reported a tertiary-level education. This could also explain why there was insufficient knowledge about zoonoses. Sixty-two (81.6\%) of the respondents were married, which implies that bushmeat hunting and processing were not mostly carried out by youth in the study area; hence, control and preventive measures for zoonosis exposure should also be targeted at this more mature group. The study identified 
that the overall level of awareness and knowledge about zoonoses among bushmeat suppliers was low, which is in line with a study done in Arusha and Tanga, Tanzania. The risk of contracting work-related diseases was high among the participants, in accordance with a previous study [10] that reported such a risk in $90.0 \%$ of the participants. Hunters were at a significantly higher risk than traders $(\mathrm{p}<0.05)$, so awareness of preventive measures should be targeted at this group as well. The results of this study showed that the majority of participants who had ever heard of zoonoses had the false belief that such diseases cannot be transmitted from bushmeat to humans in Nigeria. This incorrect belief may spread to other people within the country, ultimately contributing to poor disease control [11]. The low level of zoonotic disease awareness observed in the participants was perhaps not surprising. Approximately half of the participants knew that public health personnel and veterinarians are responsible for reporting zoonoses. This suggests that the majority of veterinarians and physicians do not regularly discuss zoonotic disease risks with bushmeat dealers [12]. This study indicated that a good number of participants valued their animals more than their health, which agrees with the previous finding [13] that the quality of bushmeat appears to be a reason why many consumers overlook the potential for disease or infection. The majority of the participants did not agree that it is the responsibility of public health personnel and veterinarians to provide information about bushmeat-associated infections or precautions to reduce the risk of these infections, which was not surprising. Although some participants expressed concerns about contracting a work-related zoonosis, exposure to infection occurred due to lack of awareness. Bushmeat hunters and traders were, for the most part, not concerned about bushmeat-associated zoonoses and were comfortable with their level of knowledge and methods to reduce zoonotic disease risk. As individuals who are not concerned, and are comfortable with their knowledge base, may be unlikely to seek additional knowledge from available resources [14], active methods may be required to improve awareness of bushmeat-associated zoonoses. A high percentage of the participants stated that they had never in their life contracted an infection from bushmeat. However, most of them reported not seeking a medical consultation regarding the possibility of a zoonotic disease when sick; instead, they sought out alternative medicines. A very large percentage of the participants stated that someone in their household had physical contact with animals outside the home on a weekly basis, which is another transmission pathway and a possible zoonotic link within the human population. Some of the respondents had good knowledge and positive attitudes about zoonotic infections, but lacked knowledge about the causative agent and the mode of transmission. Since their close associations with animals make hunters and bushmeat traders a high-risk group for contacting wildlife-associated zoonotic diseases, it is advisable that they undergo periodic health check-ups for the early diagnosis and treatment of zoonoses [15].

In conclusion, the level of knowledge, attitudes, and behaviour- al risks related to bushmeat-borne zoonoses among bushmeat dealers and hunters in Nsukka, southeast Nigeria were investigated in this study. Weaknesses were identified in knowledge and attitudes, as well as in practices that are likely to expose them to an increased risk of contracting zoonoses, as the respondents reported being unlikely to take proper precautions. Therefore, it is necessary for health personnel to educate the inhabitants of this area on the risk of zoonoses in general and to launch appropriate interventions. The establishment of bushmeat information centres in villages or at the ward level might also be useful for enhancing knowledge and skills and improving awareness and efficient control of the spread of zoonotic infections. This study provided a thorough comparison of the differences between hunters and traders in terms of knowledge, attitudes, and behavioural risk factors regarding zoonotic infections. This will help direct policymakers in providing distinctive resources corresponding to the needs or challenges of each group. It should be kept in mind, however, that participants may report answers that do not reflect their norms or state that they have common beliefs, which may impair the validity of the conclusions. Among demographic factors, age is a very important factor regarding knowledge, attitudes, and practices, but it was not separately analysed in this study since all registered hunters and traders were adults. Future research may additionally examine bushmeat consumers.

\section{ACKNOWLEDGEMENTS}

We acknowledge the Department of Zoology and Environmental Biology, University of Nigeria, Nsukka for allowing us to conduct this study. We are also grateful to the bushmeat dealers who kindly volunteered to participate in this study.

\section{CONFLICT OF INTEREST}

The authors have no conflicts of interest to declare for this study.

\section{ORCID}

Kingsley Uchenna Ozioko: http://orcid.org/0000-0001-5322-4444

\section{REFERENCES}

1. Kruse $\mathrm{H}$, kirkemo AM, Handeland K. Wildlife as source of zoonotic infections. Emerg Infect Dis 2004;10:2067-2072.

2. Kiflu B, Abdurahaman M, Alemayehu H, Eguale T. Investigation on public knowledge, attitude and practices related to pet management and zoonotic canine diseases in Addis Ababa, Ethiopia. Ethiop Vet J 2016;20:67-78.

3. Ekong PS, Juryit R, Dika NM, Nguku P, Musenero M. Prevalence and risk factors for zoonotic helminth infection among humans and animals-Jos, Nigeria, 2005-2009. Pan Afr Med J 2012;12:6.

4. Taylor LH, Latham SM, Woolhouse ME. Risk factors for human disease emergence. Philos Trans R Soc Lond B Biol Sci 2001;356: 
983-989.

5. Woolhouse ME, Gowtage-Sequeria S. Host range and emerging and reemerging pathogens. Emerg Infect Dis 2005;11:1842-1847.

6. Cleaveland S, Haydon DT, Taylor L. Overviews of pathogen emergence: which pathogens emerge, when and why? Curr Top Microbiol Immunol 2007;315:85-111.

7. Agence France-Presse (AFP). Nigeria say will prevent Ebola spread from DR Congo; 2018 May 10 [cited 2018 May 20]. Available from: https: //www.timeslive.co.za/news/africa/2018-05-10-nigeria-sayswill-prevent-ebola-spread-from-dr-congo/.

8. Okoye IC, Ozioko KU, Obiezue NR, Ikele BC. Intestinal parasitic fauna and zoonotic potentials of commonly consumed wildlife. Helminthol 2015;52:195-204.

9. Babu AJ, Ramya P, Rao LV, Swetha CS, Sudhanthiramani RK. A study on the awareness and knowledge of zoonotic diseases among the public in and around Proddatur, YSR Kadapa District, Andhra Pradesh, India. Int J Recent Sci Res 2015;6:5131-5138.

10. Swai ES, Schoonman L, Daborn CJ. Knowledge and attitude towards zoonoses among animal health workers and livestock keep- ers in Arusha and Tanga Tanzania. Tanzan J Health Res 2010;12: 280-286.

11. Omemo P, Ogola E, Omondi G, Wasonga J, Knobel D. Knowledge, attitude and practice towards zoonosis among public health workers in Nyanza province, Kenya. J Public Health Afr 2012;3: e22.

12. Grant S, Olsen CW. Preventing zoonotic diseases in immunocompromised persons: the role of physicians and veterinarians. Emerg Infect Dis 1999;5:159-163.

13. Responsive Management. African's opinions on the commercial trade and consumption of bushmeat [cited 2018 Jul 5]. Available from: http://www.responsivemanagement.com/news_from/200911-11.htm.

14. Stull JW, Peregrine AS, Sargeant JM, Weese JS. Household knowledge, attitudes and practices related to pet contact and associated zoonoses in Ontario, Canada. BMC Public Health 2012;12:553.

15. Bagaria A, Sharma AK. A Knowledge and Practices study of health hazards among animal handlers in zoological gardens. Int J Occup Saf Health 2014;4:1-4. 